\title{
Burke, Kant e Lyotard: reflexões acerca do sublime
}

\section{Burke, Kant and Lyotard: reflections on the sublime}

Micaela Lüdke Rossetti 


\section{Resumo}

O tema do sublime vem sendo desenvolvido por estudiosos desde o século XVIII na tentativa de buscar uma teoria artística a respeito desta categoria estética. Em 1757, Edmund Burke escreveu Uma investigação filosófica sobre a origem de nossas ideias do sublime e do belo; em 1790, Immanuel Kant publicou a Crítica da Faculdade Juízo; e em 1982, Jean-François Lyotard reativou o tema com a produção de $O$ sublime e a vanguarda (entre outros escritos que lançaria posteriormente). $O$ presente artigo propõe-se a apresentar as conceituações e discussões manifestadas por estes três autores acerca do belo e, principalmente, do sublime, já que Kant foi influenciado pelas ideias estéticas de Burke e Lyotard utiliza definições dos dois anteriores para formular uma nova ideia de sublime que justifica as artes de vanguarda. Para o embasamento, além dos autores citados, foram usados estudos de pesquisadores como José Thomaz Brum, Wilson Coutinho, Rodrigo Duarte, Valerio Rohden, Márcia Tiburi, e outros.

Palavras-chave: Comunicação; Filosofia; Estética, belo; Sublime.

\section{Abstract}

The theme of the sublime has been developed by scholars since the eighteenth century in an attempt to find an artistic theory about this aesthetic category. In 1757, Edmund Burke wrote A philosophical inquiry into the origin of our ideas of the sublime and the beautiful; in 1790, Immanuel Kant published the Critique of Judgment Faculty; and in 1982, JeanFrançois Lyotard reactivated the theme with the production of The sublime and the avant-garde (among other writings that he would launch later). This article aims to present the concepts and discussions expressed by these three authors about the beautiful and especially the sublime, as Kant was influenced by the aesthetic ideas of Burke and Lyotard uses the two previous definitions to formulate a new idea of sublime that justifies the avant-garde arts. To the basement, in addition to the cited authors, were used studies such as José Thomaz Brum, Wilson Coutinho, Rodrigo Duarte, Valerio Rohden, Marcia Tiburi, and others.

Keywords: Communication; Philosophy; Aesthetics, beautiful; Sublime. 


\section{Introdução}

Ao que sabemos, a arte parece ter nascido juntamente com a humanidade. Desde pinturas rupestres no interior das cavernas até os muros grafitados em diversas cidades, percebe-se a necessidade do homem de expressar-se através desta prática, que "cria objetos palpáveis ou produz manifestações concretas que ocupam um lugar dentro da realidade". (GIMENEZ, 1999, p.10).

A arte carrega um complemento abstrato, já que é manifestação do espírito e representa o mundo criando universos simbólicos ligados à nossa sensibilidade, à nossa intuição, ao nosso imaginário. Devido a isso, a filosofia dedicou-se a desvendar essa característica irracional para melhor compreender o caráter teórico da arte, e assim passou a estabelecer discussões acerca de temas como o belo, o feio, o harmonioso, 0 conveniente, o sublime.

Este trabalho propõe-se a apresentar os temas do belo e, principalmente, do sublime de acordo com o ponto de vista de três autores: Edmund Burke, Immanuel Kant e Jean-François Lyotard. Afinal, não há situação na vida em que não intervenha a beleza e o tema do sublime, categoria estética indispensável à compreensão da arte na contemporaneidade; arte esta que sofre uma crise de legitimidade que, por si só, estimula a reflexão sobre ela própria.

É importante salientar que a escolha destes três pensadores deu-se por razões específicas a cada um deles. Edmund Burke escreveu, em 1757, Uma investigação filosófica sobre a origem de nossas ideias do sublime e do belo. A obra é um marco na tradição (na época emergente) das ciências estéticas que foram bastante estudadas durante a primeira metade do século XVIII; além de ter se tornado referência indiscutível devido à análise empírica de termos estéticos e por influenciar fortemente a estética kantiana. Dentro da tradição e da crítica de arte inglesas, o filósofo é o primeiro a formular a diferença entre o belo e o sublime. (BALAGUER in BURKE, 1987).

$O$ conceito de sublime, de Immanuel Kant, foi exposto de forma sucinta em texto chamado Crítica da Faculdade do Juízo (1790). O filósofo baseou-se no temor e beleza das fúrias da natureza para discutir os problemas relativos ao belo produzido. Tal definição tornou-se um dos importantes elementos para explicar a arte moderna e contemporânea. (COUTINHO in CERÓN; REIS, 1998).

Por fim, Jean-François Lyotard reativou o tema do sublime na segunda metade do século XX com o objetivo de, pela primeira vez, apresentar as bases para uma pesquisa na direção da arte abstrata e da arte minimalista. O sublime é estado de modernidade para Lyotard, que no artigo $O$ sublime e a vanguarda (1982) e em seu livro Lições sobre a analítica do sublime (1991) abre caminho para uma estética crítica que interroga obras de arte e literárias com base nas críticas kantianas. (BRUM in CERÓN; REIS, 1998).

\section{Edmund Burke}

Edmund Burke foi um pensador irlandês nascido no ano de 1727, em Dublin, e morador da cidade de Londres a partir dos seus vinte anos. Em suas obras reuniu diversos estudos sobre filosofia, história e política - mas foi a esta última que mais se dedi- 
cou devido à formação clássica obtida na Trinity College de Dublin. Entre seus principais escritos estão Reivindicação da Sociedade Natural: uma visão das misérias e males da sociedade (1756) e Pensamentos sobre a causa do atual descontentamento (1770). (BALAGUER in BURKE, 1987).

O texto, no entanto, que traz Burke para o campo da estética é o que obteve maior destaque na sua carreira. Philosophical inquiry into the origin of our ideas of the sublime and the beautiful (Uma investigação filosófica sobre a origem das nossas ideias do sublime e o belo), lançada em 1757, foi a obra em que o pensador apresentou seus conceitos e reflexões sobre o belo e o sublime. (HUISMAN, 1994).

Menene Gras Balaguer, em Estudio Preliminar, afirma que a obra de Burke une a assimilação de filosofia e anatomia feita por cartesianos $^{1}$ e mecanicistas ${ }^{2}$, em busca da sensibilidade. Ela completa:

A reivindicação das sensações na base de todo o conhecimento deveria virar uma reivindicação de sensibilidade, que ignorava a beleza $<<$ ideal $>>$ do mundo platônico perfeito para aprender unicamente $\mathrm{o}<<$ belo $>>$.

Além da herança de Burke [...] a estética inglesa adotou, segundo predominância da metafísica e da psicologia, duas direções que levaram à formação de duas escolas opostas: a dos Intuicionistas, que contém Shaftesbury e Francis Hutcheson; e os Analíticos, os quais são incluídos Burke, junto a Joseph Adison, H. Home of Kames, William Hogarth, Archibald Alison, e o senhor Joshua Reynolds. ${ }^{3}$ (BALAGUER in BURKE, 1987, p.XIV-XV, grifo do autor, tradução nossa).

$\mathrm{Na}$ Crítica da Faculdade do Juízo (que veremos adiante) publicada vinte anos após o ensaio sobre o belo e o sublime de Burke, Kant faz alusão direta aos estudos do pensador, ampliando-os - para Kant, Burke se limitou aos juízos estéticos de uma perspectiva fisiológica, fazendo uma exposição somente empírica sobre o belo e o sublime. (BALAGUER in BURKE, 1987).

\section{Conceitos de Burke}

Em Uma investigação sobre a origem das nossas ideias sobre o sublime e o belo, Burke inicia seu escrito caracterizando alguns preceitos básicos. Para ele, o gosto diz respeito às faculdades da mente que são influenciadas por um juízo a respeito das obras da imaginação e de arte. Já a imaginação, por sua vez, é uma espécie de poder criativo representado através de imagens de "coisas" em ordem que, de acordo com a

\footnotetext{
10 cartesianismo foi um movimento intelectual do século XVII e XVIII, suscitado por René Descartes, que pregava que a filosofia era um sistema de pensamento que encarnava todo o conhecimento. Para os cartesianos, a mente estava separada do corpo físico, e a sensação e a percepção da realidade são fontes de mentiras e ilusões. WIKIPÉDIA. Base de dados. Disponível em: http:// pt.wikipedia.org/wiki/Cartesianismo. Acesso em 26 de junho de 2014, às $11 \mathrm{~h} 20$. 20 mecanicismo é uma teoria filosófica determinista na qual todos os fenômenos se explicam pela causalidade mecânica, ou em analogia a mesma. Para os mecanicistas, o universo é um mecanismo que supõe a existência de um ser superior não-mecânico (Deus). WIKIPÉDIA. Base de dados. Disponível em: <http://pt.wikipedia.org/wiki/Mecanicismo_(filosofia)> . Acesso em 26 de junho de 2014, às $11 \mathrm{~h} 39$.
}

3 La reivindicación de las sensaciones en la base de todo conocimiento suponía a su vez una reivindicación de la sensibilidad, que ignoraba la belleza <<ideal >> del mundo platónico para aprehender únicamente lo <<bello〉>. Al margen de la herencia de Burke, a la que se ha hecho alusión, la estética inglesa adopta, según predomine la metafísica o la psicología, dos direcciones que llevan a la formación de dos escuelas opuestas: la de los Intuicionistas, en la que figuran Shaftesbury y Francis Hutcheson; y la de los Analíticos, donde se incluye a Burke, junto con Joseph Adison, H. Home of Kames, William Hogarth, Archibald Alison, y sir Joshua Reynolds. (BALAGUER in BURKE, 1987, p.14-15). 
maneira com as quais são recebidas e adicionadas pelos sentidos, são recombinadas e ganham novas ordenações. O filósofo ainda salienta que nada de novo pode ser criado pela imaginação, ela somente reconfigura imagens absorvidas. A fantasia, a invenção e a inteligência pertencem à imaginação, que é também local de medos e esperanças. (BURKE, 1987).

O autor continua explicando que tanto o gosto quanto à imaginação são faculdades presentes em todos os seres humanos, que dependem unicamente da experiência e da observação:

Então, na medida em que o gosto pertence à imaginação, seu princípio é o mesmo em todos os homens; não há nenhuma diferença na maneira em que lhes afeta, nem nas causas da afeição; porém, sim existe uma diferença de grau que procede principalmente de duas causas; seja de um grau maior de sensibilidade natural, ou de uma atenção mais próxima e longa em respeito ao objeto. ${ }^{4}$ (BURKE, 1987, p.15, tradução nossa).

A intenção de Burke com sua obra é verificar se existem princípios do gosto que possam afetar a imaginação e que permitam fornecer meios para sobre eles se raciocinar. Neste ponto, o belo e o sublime surgem como frutos do trabalho da imaginação sobre os sentidos, trabalho este composto de metáforas e universalmente compreensível que permite ao homem um acordo sobre os sentidos. Devido a isso, o pensador tenta estabilizar o "binômio sublime-belo" para estabelecer um consenso entre os sujeitos e melhor garantir a chance de uma comunicação humana sobre as paixões. (BURKE, 1987).

\section{A beleza e o sublime de Burke}

A beleza para Edmund Burke é a qualidade ou as qualidades dos corpos, que são responsáveis por causar amor ou sentimentos referentes a estes, como a calma - diferente do sentimento de desejo, que seria referente a paixões violentas e tempestuosas. Ela consiste na proporção das partes (tanto de animais, quanto vegetais), mas que nada tem a ver com geometria e sim com sentidos que são confirmados pela nossa razão. Ele diz: "[...] devemos concluir que a beleza é, em sua maior parte, alguma qualidade dos corpos que atua mecanicamente sobre a mente humana mediante a intervenção dos sentidos." 5 (BURKE, 1987, p.84, tradução nossa).

De acordo com Denis Huisman (1994), para Burke o gosto é o juiz infalível do belo. Este é um sentimento de prazer positivo que resulta em um amor relaxante (que tranquiliza músculos e nervos). Ele emana do instinto social enquanto o sublime surge do instinto de conservação. O sublime do filósofo está ligado à tensão, ao hipertônus muscular, ao nervosismo. O sublime é envolto por um sentimento de "boa dor".

\footnotetext{
4 Entonces, em la medida em que El gusto pertenece a la imaginación, su principio es El mismo em todos los hombres; no hay ninguna diferencia em la manera em que les afecta, ni em las causas de La afección; pero, si hay uma diferencia de grado que procede principalmente de dos causas; sea de um grado mayor de sensibilidad natural, o de una atención más cercana y larga com respecto al objeto. (BURKE, 1987, p.15)
}

5 [...] debemos concluir que la belleza es, em su mayor parte, alguna cualidad de los cuerpos que actúa mecánicamente sobre la mente humana mediante la intervención de los sentidos. (BURKE, 1987, p.84) 
Burke fala do sublime no novo espaço de uma estética da "sensibilidade subjetiva". O prazer estético do sublime passa a ser orgânico, e o prazer e a dor do corpo se tornam molas da experiência estética. O prazer está ligado à multiplicação das espécies e a dor à conservação de si. (BRUM in CERÓN; REIS, 1998, p.60, grifo do autor).

Ainda para José Thomaz Brum, entretanto, há um caso em que essas sensações distintas são reunidas em um prazer ambíguo: o delight, o que Burke chamou da mais forte emoção que uma alma é capaz de sentir, e é a possibilidade da experiência estética do sublime. Marc Jimenez (1999) emprega outras palavras, salientando que, para Burke, o sublime é uma mistura de prazer e dor.

Outra enunciação exposta por Burke diz respeito à tipificação das paixões mais intensas, ligadas à preservação do indivíduo, como a dor e o perigo - com as quais o sublime se relaciona. Tudo o que causa terror, ou seja, relacionado ao terrível, é fonte do sublime, já que causa sensações (emoções) mais fortes do que o espírito é capaz de suportar. De acordo com o filósofo, as ideias de dor são mais poderosas do que as ideias de prazer, mas é claro que esta ideia de dor não pode ser decididamente eminente, pois seria somente terrivel; é a possibilidade, a dor atenuada que é deliciosa, no caso, delighful. "A dor que pode estar na origem do sublime provoca, no entanto, uma impressão muito menos intensa que a gerada pela ideia da morte. A dor mais insuportável, para Burke, é apenas uma emissária da morte". (SILVA, 2005).

Silva continua explicando que o sublime de Burke exige o envolvimento do espectador, exige o sentimento de perda, o encarar a morte. Ele acredita que sentimos prazer no sofrimento do outro e que o sublime é despertado por situações reais ou que sejam representadas com extrema realidade. O sentimento é tão forte que nos impede de raciocinar. (2005).

Esse "sublime da morte" que aponta para uma realidade-como-morte se manifesta tanto como a figura da privação extrema, ou seja, do real como uma falta primordial - como no caso das trevas, do vazio, da solidão, do silêncio, [...] - como também sob a figura da vastidão que nos oprime e amedronta ao revelar a nossa insignificância. (SILVA, 2005, p.34).

Essa modalidade do sublime de Burke, que está presente no vazio, é importante porque foi a primeira a considerar tal estética não presente somente na literatura, relacionando-a com o infinito. $O$ tratado do filósofo sinaliza um distanciamento às ideias clássicas e racionalistas, anunciando preocupações que seriam exploradas no período artístico do Romantismo. ${ }^{6}$

Caspar David Friedrich (1774-1840), pintor romântico alemão especialista em retratar paisagens, utilizava suas obras para despertar sentimentos religiosos e nacionalistas, transformando a arte em um transmissor de sentimentos interiores. Sua narrativa poetizava a natureza, e sua inspiração era a ponte entre o observador solitário e o ambiente externo. Em suas telas, céus grandiosos, cruzes, tempestades, ruínas e símbolos

6. ITAÚ CULTURAL. Site. Disponível em: <http://www.taucultural.org.br/ aplicexternas/enciclopedia_ic/index.cfm?fuseaction=termos_texto\&cd_verbete $=3655>$. Acesso em 27 de junho de 2014, às 12 h41. 
da morte eram frequentes. Ou seja, a calma da beleza suscitada pela natureza era unida à dor, ao perigo, ao terrivel dos símbolos e do vazio, causando o delight de Burke através da imaginação do indivíduo (Fig. 1).

Figura 1 - Morning in the Riesengebirge, 1810, de Casper David Friedrich.

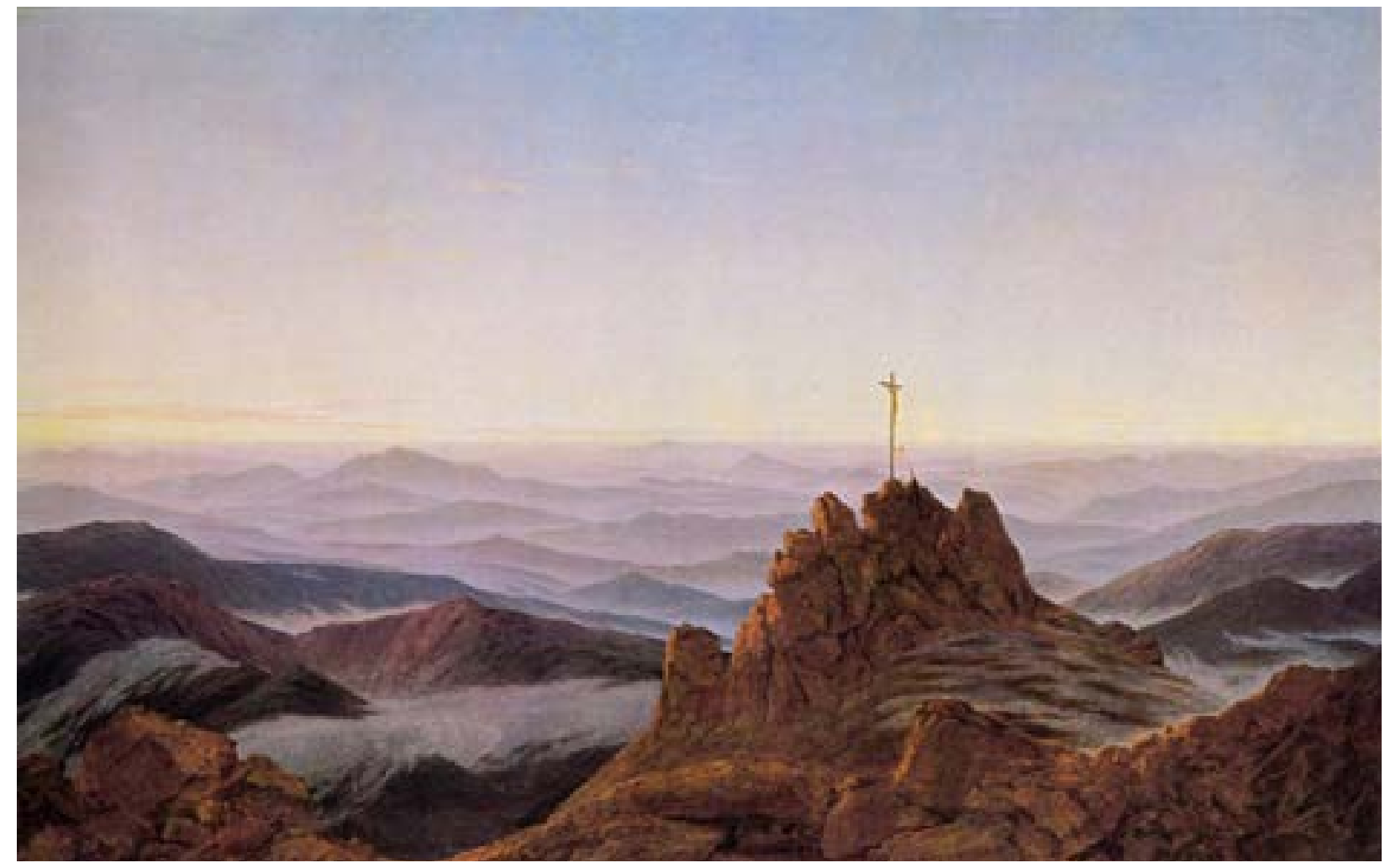

Fonte: http://upload.wikimedia.org/wikipedia/commons/6/62/Caspar_David_Friedrich,_Morgen_im_Riesengebirge.jpg (2014).

As pinturas de William Turner (1775-1851), artista pertencente ao romantismo inglês, também evocavam sentimentos de sublime de acordo com as definições de Burke. Suas obras retratavam a natureza e principalmente a água (o mar era uma constante, assim com a cidade de Veneza), despertando no espectador sentidos confirmados pela razão. Entretanto, ao mesmo tempo, tempestades, agitação do mar e o uso de cores mais densas e escuras transportavam a imaginação para um local tenso, de possibilidade de morte (Fig. 2). 
Figura 2 - Snow Storm. Steam-Boat off a Harbour's Mouth , 1842, de William Turner.

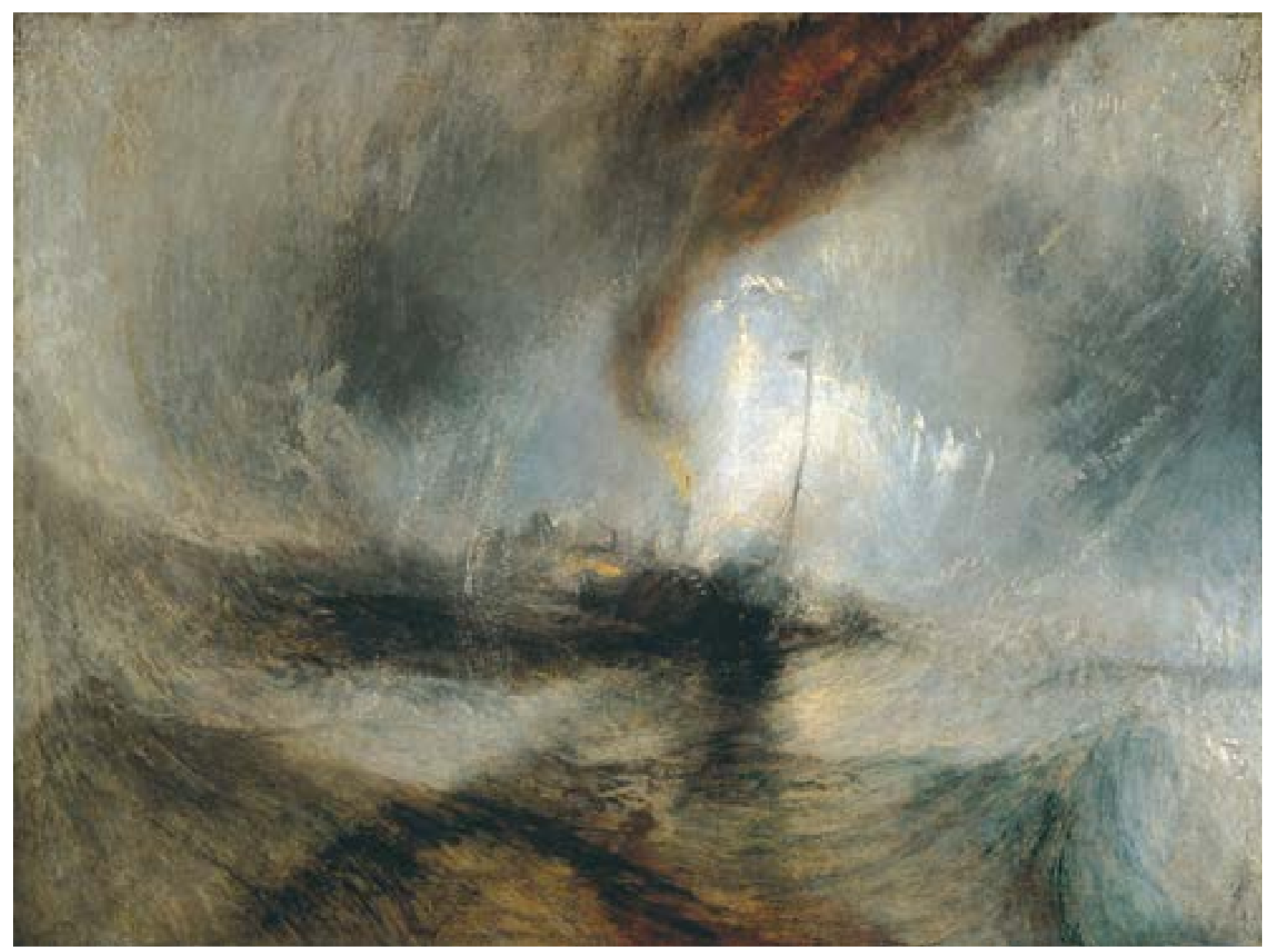

Fonte: http://upload.wikimedia.org/wikipedia/commons/3/30/Joseph_Mallord_William_Turner_-_Snow_Storm_-_Steam-Boat_off_a_Harbour's_ Mouth_-_WGA23178.jpg (2014).

\section{Immanuel Kant}

Immanuel Kant nasceu em 22 de abril de 1724 (em Königsberg, Prússia) e é considerado um dos grandes filósofos dos princípios da era moderna. Tendo vivido toda a sua vida na mesma cidade, dedicou-se a estudar filosofia, matemática e física e publicou sua primeira obra, chamada A Crítica da Razão Pura, em 1781. No livro - considerado uma das mais importantes e influentes obras da filosofia moderna, Kant se dedicou a fixar os limites de conhecimento que podemos ter do mundo e decidir sobre a legitimidade das investigações metafísicas sobre Deus, a alma e o mundo. (GUYER, 2014).

Nos vinte anos seguintes, Kant publicou incessantemente. Entre os títulos estão Fundamentos da Metafísica dos Costumes (1785), A Crítica da Razão Prática (1788) e A Crítica do Julgamento ou Crítica da Faculdade do Juízo (1790). Nesse último, o filósofo apresenta os conceitos de juízo estético e investiga os limites daquilo que pode ser conhecido pela nossa faculdade de julgar, através da união da razão, sentimentos e 
memória. ${ }^{7}$

Segundo José Henrique Santos, A Crítica da Faculdade de Juízo diferencia-se das duas primeiras, pois

Já não se trata de elevar a receptividade pondo-a de acordo com a síntese a priori dos conceitos do entendimento (filosofia teórica), nem de encontrar o fundamento da ação prática na síntese a priori da vontade (filosofia prática), mas tão somente de encontrar os princípios a priori que nos permitam julgar a arte e a natureza como coisas belas, sem nada acrescentar ao que sabíamos antes, e de julgar a natureza segundo uma finalidade apenas presumida, de modo puramente reflexivo, sem qualquer valor de conhecimento. (SANTOS in DUARTE, 1998, p.21, grifo do autor).

De acordo com Jens Kulenkampff (in DUARTE, 1998), a obra, apesar de tardia, vem para comprovar um gosto que Kant demonstrou durante toda a sua vida. Em conferências de Antropologia e Lógica, o filósofo já falava sobre estética e é no citado escrito que encontramos as discussões sobre o belo e o sublime - sentimentos do sujeito - que exerceram grande influência no mundo da cultura e imediatamente posterior a Kant.

\section{Juízo de gosto: o belo para Kant}

Para entendermos o juízo de Immanuel Kant é preciso, primeiro, compreender que para ele existem diferenças claras e importantes entre os domínios estéticos e cognitivos. Valério Rohden (in DUARTE, 1998) explica que, na base da concepção kantiana de conhecimento, é encontrada uma relação entre representação e realidade (que seriam conceito e intuição) que permite a identificação do objeto como conhecido. Para Kant, o entendimento não intui e os sentidos não pensam. $O$ juízo é, portanto, uma atividade cognitiva que pela autoconsciência termina na determinação de um objeto. Ou seja, o conhecimento de objetos supõe uma atividade de nossa consciência, que liga representações segundo a necessidade de certas regras.

$\mathrm{Na}$ Crítica da Faculdade do Juízo, a relação entre conhecimento e juízo é alterada devido ao juízo de gosto, que é visto como transcendental - a representação da condição universal do conhecimento em geral dos objetos. Ou seja, o juízo de gosto justifica a priori o princípio subjetivo do gosto e o entendimento está presente, mas com uma função não cognitiva, estabelecendo a relação entre representação e sujeito.

O juízo de gosto é um juízo sobre a beleza de um objeto representado, posto em relação com o sujeito pelas faculdades da imaginação e do entendimento. $\mathrm{O}$ juízo afirma a priori um pretenso significado universal da beleza. A relação que o entendimento estabelece entre a representação da imaginação e o sujeito envolve todos os sujeitos em potencial relação com a representação dada. A beleza é uma forma desse objeto, ajuizada como um jogo entre as faculdades do conhecimento. (ROHDEN in DUARTE, 1998, p.65-66, grifo do autor).

A distinção do belo (objeto de satisfação universal que representa uma cumpli-

7 WIKIPÉDIA. Base de dados. Disponível em: <http://pt.wikipedia.org/wiki/

Immanuel_Kant>. Acesso em 19 de junho de 2014. 
cidade entre o juízo estético e sensível) dá-se quando referimos a representação não ao objeto em vista do conhecimento, mas ao sujeito e ao seu sentimento de prazer ou desprazer. O juízo de gosto puro não é um juízo de conhecimento, mas sim estético, sensivel, que se entende como aquilo cujo fundamento de determinação não pode ser senão subjetivo. Kant afirmou que juízos estéticos puros apenas têm a ver com a forma ou a configuração intuitiva dos objetos, pois "existem configurações de objetos e formas intuitivas suficientemente múltiplas e suficientemente unitárias para satisfazer nossas necessidades cognitivas por clareza e simplicidade ao mesmo tempo". (KULENKAMPFF in DUARTE, 1998, p.48).

Para Kant, em proximidade com o pensamento de Burke, a percepção estética utiliza faculdades mentais que todas as pessoas possuem se aptas para o conhecimento - independente de cultura e nível social: entendimento (explicado anteriormente) e imaginação.

A imaginação é uma "livre legalidade" que só pode ser determinada por reprodução, mas se determina ela mesma livremente: ela é "produtiva e espontânea". Encontramos aqui este "tudo se dá como se", que Kant usa à saciedade: tudo se dá, com efeito, como se a imaginação fosse "criadora de formas arbitrárias e intuições possíveis". Pois, imediatamente, o filósofo concede que a imaginação precisa do objeto, embora parecesse que ela "não tenha um livre jogo (como na poesia)”. (CHATEAU in CERÓN; REIS, 1998, p.74, grifo do autor).

Ainda de acordo com Dominique Chateau (in CERÓN; REIS; 1998), o juízo de gosto de Kant é singular, já que se aplica ao indivíduo no sentido lógico, e é propriedade exclusiva deste indivíduo, pois pertence somente a um ponto de vista. Por exemplo: uma flor é bela, mas esta determinada flor é observada do ponto de vista de uma determinada pessoa; não são todas as flores belas em um sentido geral, para todos os seres humanos.

Wilson Coutinho esclarece que, na Crítica da Faculdade do Juízo, Kant possibilita o discurso intersubjetivo: "Se eu achar algo belo e o outro diz que não é, o que temos em comum é a possibilidade racional da existência da beleza, mas também é racional que nós possamos discordar e concordar". (in CERÓN; REIS, 1998, p.18-19). É neste momento que o filósofo nos propõe um espaço de comunicação e sociabilidade, que é comum ao ser humano.

O belo kantiano é a forma de um objeto sem representação de fim, sua finalidade está em si mesmo. Ele convém às faculdades humanas e, por isso, agrada. $O$ belo provoca o prazer, que é o cerne da experiência estética e que surge da percepção da adequação entre a faculdade e o objeto do conhecimento. $O$ belo é fruto da relação entre imaginação e entendimento. (TIBURI in DUARTE, 1998).

\section{O sublime para Kant}

$\mathrm{Na}$ Crítica da Faculdade do Juízo, Kant apresenta no sublime a autocrítica da imaginação no momento em que ela se depara com a irrepresentabilidade das ideias de infinito, liberdade e totalidade. Marco Heleno Barreto (in DUARTE, 1998) explica que na experiência do sublime o espírito é incitado a abandonar o entendimento apresentado 
no belo, para dar espaço à razão - que, por sua vez, violenta a imaginação. O sublime não está contido no sensível, mas concerne a ideias da razão. Ele "abre para a estética a possibilidade de ver a representação se anular e o sentimento de respeito por ele evocado surge justamente no lugar deixado vazio por tal anulação". (p.174).

O sublime tem como relação primordial a imaginação e a razão. Ele surge da relação tensa entre essas duas faculdades, pois a razão tem dificuldade em adequar-se à imaginação. Márcia Tiburi argumenta: "O sublime é o sentimento que surge de uma espécie de fuga da razão do sensível" e "a imaginação, ao entrar em luta com a razão que exige dela a 'apresentação do não apresentável'". (in DUARTE, 1998, p.240, grifo do autor). Ou seja, o que é sublime não é nem objeto, nem a razão, mas sim o movimento da imaginação para apresentar as ideias da razão.

Esse movimento independe da natureza e da nossa personalidade moral. Os fenômenos estéticos só se chamam assim para nos conscientizarmos da indestrutibilidade da humanidade em nossa pessoa, da nossa superioridade sensível sobre a natureza frente a um espetáculo de forças naturais, às quais iríamos sucumbir se expostos a elas. (KULENKAMPFF in DUARTE, 1998). O sublime de Kant está ligado à experiência estética da natureza e de sua infinidade.

Na passagem do belo para o sublime, passamos também da arte para a natureza. Mas, ao fazê-lo, colocamos a natureza sob o domínio da faculdade da imaginação. Pois, com efeito, o sublime só existe na natureza, é o que é "absolutamente grande" ou ainda "aquilo em comparação com o qual tudo o mais é pequeno" e que, deste modo, "ultrapassa todo o padrão de medida dos sentidos". (SANTOS in DUARTE, 1998, p.31, grifo do autor).

José Thomaz Brum, em Visões do Sublime: de Kant a Lyotard (in CERÓN; REIS, 1998), explica que o sublime kantiano revela a experiência primordial da finitude humana, já que em face das forças naturais que, pela potência, esmagam o homem (sublime dinâmico) e a grandezas incomparáveis que, por sua infinidade, o ultrapassam (sublime matemático); ele se reconhece pela consciência limitada e faz uma experiência estética da finitude - em última instância, a morte.

O sublime kantiano faz com que o homem se realize, transcendentalmente, a experiência da infinidade; e isso no seu novo lar: a interioridade subjetiva. $\mathrm{O}$ sublime não pertence aos objetos, nem às obras de arte, segundo Kant. Ele é um sentimento transcendental negativo que faz com que o homem sinta a sua impotência ante o absoluto inteligível. (BRUM in CERÓN; REIS, 1998, p.62, grifo do autor).

No sublime, em vez do agrado imediato, ocasionado pelo livre jogo entre entendimento e imaginação, o prazer é mediado por um desprazer inicial "fruto da sobrecarga da imaginação no intuito de apresentar à faculdade cognitiva algo de magnitude tal que não pode ser dado em uma intuição sensível". (DUARTE in CERÓN; REIS, 1998, p.95). Barreto (in DUARTE, 1998) salienta que o estado de ânimo que propicia a experiência sublime parte desta turbulência, deste conflito interno, movimento que se resolve no final com a harmonia entre a razão e a imaginação.

Luiz Camillo Osório, em Uma leitura contemporânea da estética de Kant, com- 
plementa, afirmando que o sublime de Kant é uma espécie de contraintuição que nega inicialmente a unidade. Esta ruptura violenta da unidade de espaço e tempo é o que desesquematiza o mundo. "O sentimento do sublime nos traz para o instante onde se quebra o encadeamento dos fenômenos, onde ele ainda não se configura como forma, como medida". (in CERÓN; REIS, 1998, p.234). Devido a isso, o sublime também apresenta medo, já que é o infinito, a indeterminação.

Tais definições de Kant acabaram por influenciar ideias e obras do Neoclassicismo, que perderam a valorização da graça em prol da ideia de uma beleza sublime. $O$ escultor dinamarquês Bertel Thorvaldsen (1770-1844) foi um dos representantes mais famosos deste ideal, e suas obras são expoentes da fusão da arte da Antiguidade Clássica com ideias de liberdade, igualdade e fraternidade. $O$ artista encarnou o estilo de arte grega clássica através do uso de formas mais rígidas e formais, com inspiração na mitologia grega. A razão esmaga a imaginação nas esculturas de Thorvaldsen, já que as ideias da forma prevalecem nas obras; e o homem experiencia a ideia de finitude, de um trabalho completo e "acabado" (Fig.3).

Figura 3 - Nessus Abducting Deianira, 1814, de Bertel Thorvaldsen.

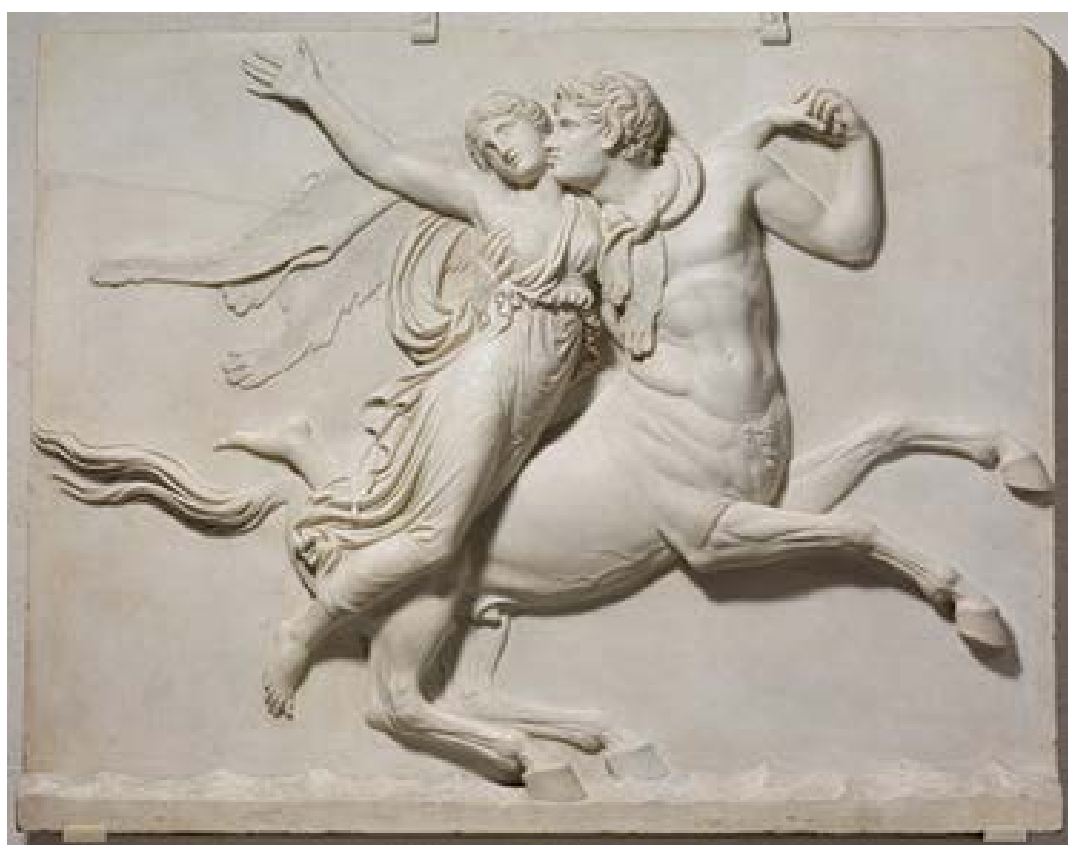

Fonte: http://www.metmuseum.org/toah/images/h2/h2_2004.174.jpg (2014).

Jean-François Lyotard

Entre os pensadores franceses mais interessados na discussão da pós-modernidade, Jean-François Lyotard nasceu em 1924, na cidade de Versalhes, França. Filósofo, sociólogo e teórico literário, trabalhou com diversas áreas do conhecimento, entre elas a comunicação, o corpo humano, a arte modernista e pós-moderna, a literatura, a música, o cinema, o tempo, a memória, o sublime, a relação entre a estética e a política, 
etc. ${ }^{8}$

Cofundador do Colégio Internacional de Filosofia (ao lado de Jacques Derrida, François Châtelet e Gilles Deleuze), apresenta em sua obra mais importante, chamada A Condição Pós-Moderna (1979), discussões acerca da estética, da sociedade, da literatura e da filosofia pós-modernas, sinalizando tal condição como uma consequência da crise do capitalismo e não como um sintoma do surgimento de uma sociedade pós- capitalista/industrial. (JIMENEZ, 1999).

O tema do sublime, entretanto, aparece pela primeira vez somente em um artigo publicado pela Artforum em 1982, chamado Le sublime et l'avant-garde (O sublime e a vanguarda). O escrito relaciona o sublime com a vanguarda artística e explicita, pela primeira vez, uma ideia interessante:

[...] com a visão kantiana de que, na experiência do sublime, ocorre uma apresentação negativa - ou um fracasso na tentativa de representar o absoluto -, estão lançadas as bases para uma "pesquisa na direção da arte abstrata e da arte minimal". A sua teoria é de que "a vanguarda está assim em germe na estética kantiana do sublime". (BRUM in CERÓN; REIS, 1998, p.64, grifo do autor)

Tal artigo deu início à discussão estética do sublime feita por Lyotard, que culminou com o desenvolvimento de diversos escritos e da obra Lições sobre a analítica do sublime, lançada em 1991. No livro, o filósofo faz uma releitura de parte da obra Crítica da Faculdade do Juízo, de Kant, na tentativa de compreender o sentimento do sublime.

\section{O tema do sublime para Lyotard}

Jean-François Lyotard carrega o tema do sublime para o final do século XX, colocando-o em contato com as artes de vanguarda. Sua discussão baseia-se em algumas definições já feitas por Burke e Kant (apresentadas anteriormente), mas exprime novas e interessantes ideias a serem consideradas.

O sentimento de sublime para Lyotard é visto como o modo de sensibilidade característico da modernidade e é através dele que este período artístico se manifesta. Em sua obra O Inumano: considerações sobre o tempo (1990), o pensador explica:

Este sentimento contraditório, prazer e dor, felicidade e angústia, exaltação e depressão, foi batizado ou rebatizado, entre o século XVII e o século XVIII europeus, com o nome de sublime. Foi nesta palavra que se decidiu e se perdeu a sorte da poética clássica, sobre a arte, e que o romantismo, ou seja o modernismo, triunfou. (1997, p.98, grifo do autor).

Para Lyotard, quando a arte moderna passou a apresentar o "inapresentável", ela se libertou da sua natureza, viu-se livre de preconceitos do senso comum perceptivo, e passou a se aventurar em um campo livre de toda a representação empírica. Ela assumiu-se como "simulacro e parte - como no sublime kantiano - para uma região

8 WIKIPÉDIA. Base de dados. Disponível em: <http://en.wikipedia.org/wiki/ Jean-Fran\%C3\%A7ois_Lyotard>. Acesso em 27 de junho de 2014, às $13 \mathrm{~h} 17$. 
estranha ao tema do visível e de sua figurabilidade." (BRUM in CERÓN; REIS, 1998, p.64, grifo do autor).

Ainda de acordo com José Thomaz Brum, o sublime é estado de modernidade estética para Lyotard, quando modernidade é a experiência humana que não tem fim da historicidade. O sublime, que no romantismo foi uma experiência estética do inexprimível, na modernidade é uma intensificação do gesto expressivo, que é também gesto reflexivo.

A obra de arte "moderna", no dizer de Lyotard, fala de um impessoal acontecimento, de uma espécie de imediaticidade ontológica em que, sem símbolos, sem representações, se aluda ao vazio e ao desamparo metafísicos da contemporaneidade. (BRUM in CERÓN; REIS, 1998, p.65, grifo do autor).

O filósofo busca nas ideias Burke a questão deste acontecimento, desta imediaticidade, do tempo no sublime, que para Lyotard reside na ideia de que o inexprimível, o irrepresentável, não se encontra num além, num outro mundo, mas no aqui, no agora, na ansiedade para que algo ocorra. Para Burke o sublime é provocado pelo vazio, que é uma ameaça de nada acontecer, pela privação, pela ideia de (como vimos anteriormente). Lyotard chama essa sensação de Ocorrerá? e explica que o sentimento do sublime é "um objeto muito grande, muito poderoso, que ameaça privar a alma de toda e qualquer Ocorrência que a <<espanta>> (em graus de intensidade menores a alma sente admiração, veneração, respeito)". (LYOTARD, 1997, p.104, grifo do autor). Quando este sentimento ameaçador de privação, vazio, se afasta, provoca a delícia, o delighful para Burke.

Lyotard afirma que, com a estética do sublime em mente, as artes não precisam se preocupar em suscitar sentimentos de beleza, imitando modelos já conhecidos. Elas devem buscar efeitos intensos, combinações surpreendentes, chocantes, para que aconteça algo, Ocorra algo (dentro do expectador, na imaginação) ao invés do nada.

Segundo Márcia Tiburi, para Lyotard a imaginação só é capaz de sintetizar grandezas, ou seja, se estas não excedem a medida primeira de sua compreensão - uma medida absoluta subjetiva. (in DUARTE, 1998).

Não é a toa que Jean-François Lyotard adota o mecanismo dos deslocamentos sucessivos para analisar entre outras questões que compõem a "Analítica do Sublime", a da magnitudo. Segundo aquele autor, só equivocadamente é que a magnitudo qualifica o objeto dito "absolutamente grande". Na verdade, ele continua, considerando os deslizamentos do sublime dentro da classificação categorial, a quantidade lógica do juízo sublime (ele é um juízo singular e universal) passa à modalidade (ele é um juízo necessário) através da relação (de finalidade entre as faculdades). (FIGUEIREDO in DUARTE, 1998, p.259).

Dessa forma, a magnitudo - no sublime - está relacionada ao sentimento de prazer e dor, não ao objeto. O sentimento do sublime é absolutamente grande, uma exigência do aumento da nossa alma para que ela se adapte ao infinito e, como para Kant, impossível de presentificação - o que inibe a concordância das faculdades concordantes no belo e desafia a Ideia frente ao desastre da imaginação.

Lyotard deixa claro, em Lições sobre a analítica do sublime, que o pensamento ocasionado pelo sentimento de sublime só se relaciona com a natureza neste quesi- 
to de qualidades capazes de gerar grandeza ou uma força que ultrapassa o poder de apresentação. O pensamento então se torna surdo ou cego à beleza natural, já que se vê impotente. "Dir-se-á que o pensamento, no sentimento sublime, impacienta-se, desespera-se, desinteressa-se em atingir os fins da liberdade pelos meios de natureza". (LYOTARD, 1993, p.55). Ele experimenta sua própria finalidade pelo meio de uma forma ou da ausência da forma.

É a união da grandeza, da potência infinita do sublime de Kant, com o vazio, a privação do sublime de Burke, que resulta no sublime de Lyotard. Essa união foi o que as artes de vanguarda provocaram mesmo que os artistas da época não tivessem lido Burke ou Kant. Elas experimentaram para permitir o acontecimento, buscaram provocar sensações, aproximaram o público do sublime e, por isso, acabaram por ser rejeitadas inicialmente pela comunidade social, que não mais se reconhecia nos produtos artísticos. (LYOTARD, 1997). O sublime é para Lyotard, portanto, a justificativa teórica para as artes de vanguarda terem deixado de se orientar pelo belo, ponto comum às estéticas artísticas anteriores a elas.

Marcel Duchamp (1887-1968) é um destes artistas experimentais, que através dos ready-mades buscou o sentimento de sublime de Lyotard. Os ready-mades são obras de arte que utilizam objetos industrializados, desprezando noções comuns à arte histórica e valorizando o objeto em si. Eles experimentam sua própria finalidade por meio de uma forma ou da ausência de forma e tem como finalidade um efeito intenso, surpreendente. Entre os mais conhecidos de Duchamp está A Fonte, obra que consistia em um urinol feito sob encomenda pelo artista para concorrer a um concurso de arte estadonidense. A peça foi negada por não possuir caráter artístico, mas tornou-se um dos mais destacados trabalhos do francês (Fig. 4).

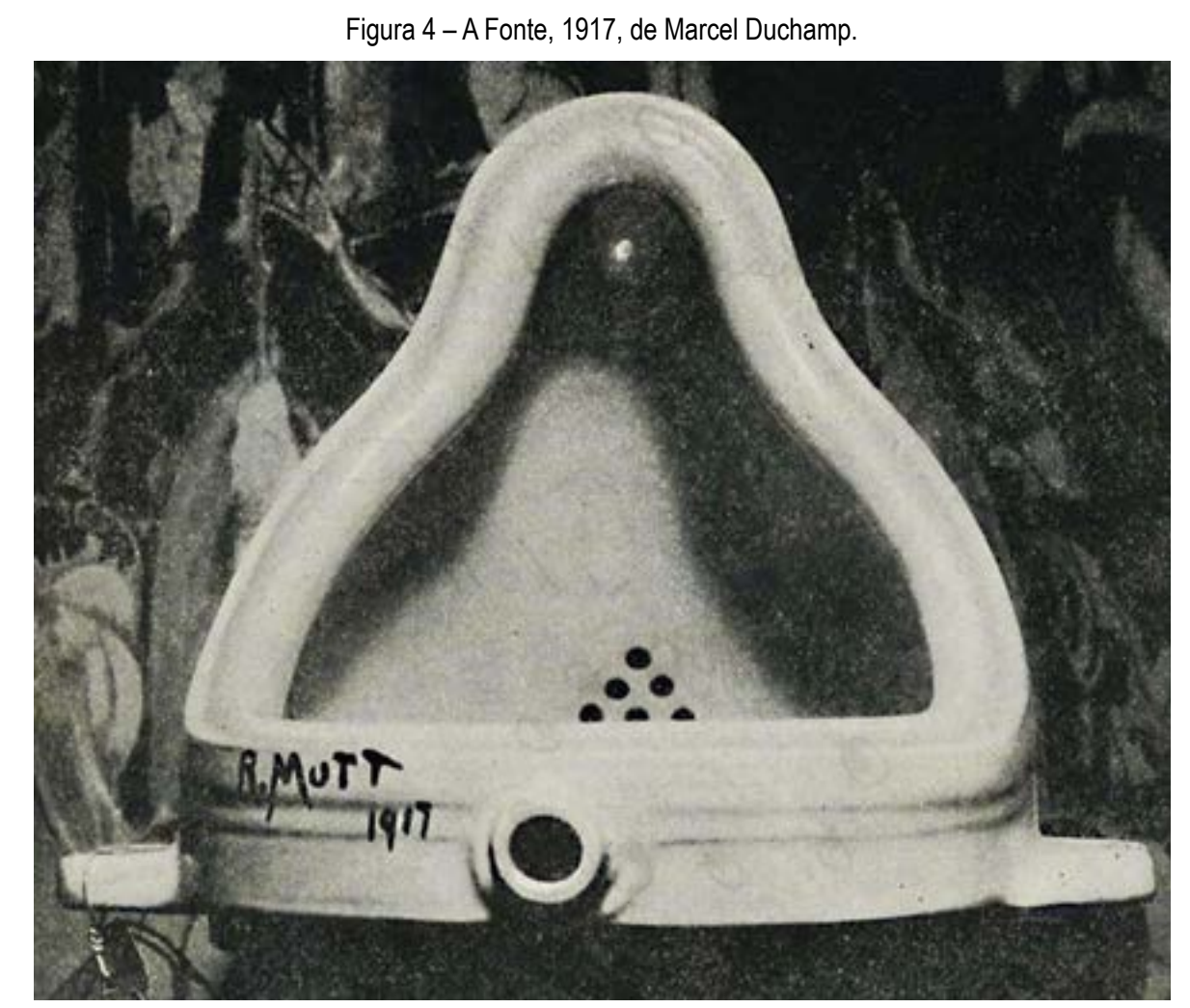

Fonte: http://3.bp.blogspot.com/- 0C2EOloGe20/Td_jAOh4_MI/AAAAAAABDrA/qxVPW_nALA8/s1600/Duchamp_Founta ine.jpg (2014). 
Esse conceito de sublime explicitado por Lyotard provocou e exigiu uma alteração nas técnicas artísticas e nas instituições a ela ligadas, como Academias, Escolas e professores de arte. O que interessa da arte de vanguarda em diante não é quem é o artista (destinador) ou como produziu sua obra. Trata-se agora de surpreender o expectador, de estudar o destinatário, as maneiras de afetá-lo, de como ele recebe as obras e como as julga. (LYOTARD, 1997).

\section{Considerações finais}

Em um momento em que cada vez mais se proliferam artistas e obras de arte e que grande parte da população - independente da classe social - tem acesso à produção artística mundial, torna-se indispensável para os estudiosos da área o conhecimento e a análise das teorias da arte, assim como de categorias estéticas como o belo e o sublime.

Para Edmund Burke, o belo é calmo e o sublime é um choque, um sentido, suscita ideias de dor, de perigo e de horror, é o vazio. Para Immanuel Kant, o belo é finito, completo e gera harmonia, enquanto o sublime é infinito, grande, uma potência que gera luta entre a razão e a imaginação. E, para Jean-François Lyotard, o sublime é o vazio, o Ocorrerá?, sendo também uma grandeza, uma potência que inibe o pensamento.

Através deste último, as teorias de Burke e Kant acerca do belo e do sublime ganham destaque na contemporaneidade e tornam-se essenciais para pensar a arte do século XX. Também devem ser consideradas quando questionamos a arte contemporânea, analisamos as obras e buscamos compreender sensações suscitadas por elas. Ainda se pode sentir a calmaria do belo de Burke ou o choque do seu sublime nos produtos artísticos produzidos atualmente, como filmes e fotografias? A luta entre razão e imaginação sugerida por Kant pode ser resultado de uma visita ao teatro ou da audição de um álbum de música? O vazio de Lyotard é uma consequência das artes chamadas digitais, como design ou videogames?

É possível dizer que o belo e o sublime são sentimentos eternos, e que as ideias destes três pensadores poderão (e deverão) permanecer em evidência quando se discutem as artes plásticas, o cinema, a música, o teatro e outras. Uma das grandes questões da atualidade artística não é discernir o que é arte e o que não é? Talvez Burke, Kant, Lyotard e tantos outros que se dedicaram a entender a estética e suas categorias possam contribuir na busca pela resposta a essa pergunta.

\section{Referências bibliográficas}

BALAGUER, Menene Gras. Estudio preliminar. In: BURKE, Edmund. Indagación filosófica sobre el origen de nuestras ideas acerca de lo sublime y de ló bello. Traducción de Menene Gras Balaguer. España: Editorial Tecnos S.A., 1987.

BARRETO, Marco Heleno. A imaginação e o sublime - herança de um pavor: de 
Kant a Bachelard. In: DUARTE, Rodrigo. (Org.) O belo, o sublime e Kant. Belo Horizonte: Editora UFMG, 1998.

BRUM, José Thomaz. Visões do sublime: de Kant a Lyotard. In: CERÓN, Ileana Pradilla; REIS, Paulo. (Org.) Kant: crítica e estética na modernidade. São Paulo: Editora Senac, 1998.

BURKE, Edmund. Indagación filosófica sobre el origen de nuestras ideas acerca de lo sublime y de ló bello. Traducción de Menene Gras Balaguer. España: Editorial Tecnos S.A., 1987.

CERÓN, Ileana Pradilla; REIS, Paulo. (Org.) Kant: crítica e estética na modernidade. São Paulo: Editora Senac, 1998.

CHATEAU, Dominique. O objetivismo de Kant. In: CERÓN, Ileana Pradilla; REIS, Paulo. (Org.) Kant: crítica e estética na modernidade. São Paulo: Editora Senac, 1998.

COUTINHO, Wilson. Kant contra a banalidade da arte. In: CERÓN, Ileana Pradilla; REIS, Paulo. (Org.) Kant: crítica e estética na modernidade. São Paulo: Editora Senac, 1998.

DUARTE, Rodrigo. (Org.) O belo, o sublime e Kant. Belo Horizonte: Editora UFMG, 1998.

DUARTE, Rodrigo. Sobre o feio e o repulsivo: de Kant a Schopenhauer. In: CERÓN, Ileana Pradilla; REIS, Paulo. (Org.) Kant: crítica e estética na modernidade. São Paulo: Editora Senac, 1998.

FIGUEIREDO, Virgínia. Observações sobre a estética de Kant. In: DUARTE, Rodrigo. (Org.) O belo, o sublime e Kant. Belo Horizonte: Editora UFMG, 1998.

HUISMAN, Denis. A Estética. Tradução do Gabinete Editorial de Edições 70. Lisboa: Edições 70, 1994.

GUYER, Paul. Kant. 2ª edição. Nova York: Routlege, 2014.

JIMENEZ, Marc. O que é estética? Tradução de Fulvia M. L. Moretto. São Leopoldo, RS: Ed. UNISINOS, 1999.

KANT , Immanuel. Crítica da Faculdade do Juízo. Tradução de Valério Rohden e António Marques. Rio de Janeiro: Editora Forense Universitária, 1993.

KULENKAMPFF, Jens. A estética kantiana entre antropologia e filosofia transcendental. In: DUARTE, Rodrigo. (Org.) O belo, o sublime e Kant. Belo Horizonte: Editora 
UFMG, 1998.

LYOTARD, Jean-François. Lições sobre a analítica do sublime. Tradução de Contança Marcondes Cesar e Lucy R. Moreira Cesar. Campinas, SP: Papirus, 1993.

Jean-François. O inumano: considerações sobre o tempo. $2^{\text {a }}$ ed. Tradução de Ana Cristina Seabra e Elisabete Alexandre. Lisboa: Editorial Estampa, 1997.

OSÓRIO, Luiz Camillo. Uma leitura contemporânea da estética e Kant. In: CERÓN, Ileana Pradilla; REIS, Paulo. (Org.) Kant: crítica e estética na modernidade. São Paulo: Editora Senac, 1998.

ROHDEN, Valerio. Aparências estéticas não enganam - sobre a relação entre juízo de gosto e conhecimento em Kant. In: DUARTE, Rodrigo. (Org.) O belo, o sublime e Kant. Belo Horizonte: Editora UFMG, 1998.

SANTOS, José Henrique. O lugar da crítica da faculdade de juízo na crítica de Kant. In: DUARTE, Rodrigo. (Org.) O belo, o sublime e Kant. Belo Horizonte: Editora UFMG, 1998.

SILVA, Márcio Selligman. O local da diferença: ensaios sobre memória, arte, literatura e tradução. São Paulo: Editora 34, 2005.

TIBURI, Márcia. Kant, o sublime e a natureza ou o sonho da razão. In: DUARTE, Rodrigo. (Org.) O belo, o sublime e Kant. Belo Horizonte: Editora UFMG, 1998.

\section{Sites}

ITAÚ CULTURAL. Site. Disponível em: <http://www.itaucultural.org.br/aplicexternas/enciclopedia_ic/index.cfm?fuseaction=termos_texto\&cd_verbete $=3655>$. Acesso em 27 de junho de 2014, às $12 \mathrm{~h} 41$.

WIKIPÉDIA. Base de dados. Disponível em: <http://pt.wikipedia.org/wiki/lmmanuel_Kant>. Acesso em 19 de junho de 2014.

WIKIPÉDIA. Base de dados. Disponível em: http://pt.wikipedia.org/wiki/Cartesianismo. Acesso em 26 de junho de 2014, às $11 \mathrm{~h} 20$.

WIKIPÉDIA. Base de dados. Disponível em: <http://pt.wikipedia.org/wiki/Mecanicismo_(filosofia)>. Acesso em 26 de junho de 2014, às 11h39.

WIKIPÉDIA. Base de dados. Disponível em: <http://en.wikipedia.org/wiki/Jean-Fran\%C3\%A7ois_Lyotard>. Acesso em 27 de junho de 2014, às 13 h17. 


\section{Autor}

\section{Micaela Lüdke Rossetti}

Mestranda do Programa de Pós-Graduação em Comunicação Social da Pontifícia Universidade Católica do Rio Grande do Sul (PPGCOM PUCRS) e graduada em Comunicação Social Jornalismo pela Universidade de Caxias do Sul (UCS)

Porto Alegre, Rio Grande do Sul, Brasil

micaela.rossettiahotmail.com

http://lattes.cnpq.br/2472558017641879 